\title{
História oral e fragmentos da cultura popular cabocla
}

\author{
Délcio Marquetti* \\ Juraci Brandalize Lopes da Silva ${ }^{\star \star}$
}

\begin{abstract}
Resumo: O presente artigo expõe experiências com Abstract: The present article expounds experiences História Oral e reconstituição da cultura popular em with Oral History and rebuilding of the popular culture torno da crença no monge João Maria D’Agostini, around the faith in the monk Agostini João Maria, presente em populações caboclas do município de present in the caboclo populations of the municipal Xanxerê, SC, construídas enquanto parte do projeto district of Xanxerê, SC, and built as part of the project "História e Memória de Xanxerê", do Programa de " History and Memory of Xanxerê ", of the Regional Alfabetização Regional, desenvolvido pela Literacy Program developed by the University of the Universidade do Oeste de Santa Catarina - Unoesc, West of Santa Catarina - Unoesc, Campus of Xanxerê, Campus de Xanxerê, desde o ano de 2007. Populações since the year of 2007. Caboclo Populations of the area caboclas da região possuem rico acervo de cultura have a rich collection of popular culture which is popular que se encontra registrado em suas memórias, registered in their memories, and has been suffering e que vêm sofrendo profundas alterações com o avanço deep alterations with the progress of the productive das forças produtivas. forces.
\end{abstract}

Palavras-chave: Monge João Maria D’Agostini; Keywords: Monk Agostini João Maria; popular cultura popular; memória; religiosidade. culture; memory; religiosity.

\section{Introdução}

O Programa Alfabetização Regional iniciou suas atividades em março de 2007, vinculado a uma nova proposta pedagógica para a formação de profissionais da educação básica na Universidade do Oeste de Santa Catarina - Unoesc, Campus de Xanxerê. O programa apóia-se em pressupostos formativos comprometidos com uma qualificação profissional que compreenda competência técnico-científica e política, sensibilidade ética e solidariedade social, constituindo-se em importante espaço para as atividades de ensino, pesquisa e extensão.

\footnotetext{
* Mestre em História - Área de concentração História Regional, pela Universidade de Passo Fundo (UPF). Professor na Universidade do Oeste de Santa Catarina - UNOESC, Campus de Xanxerê. Autor do artigo Colonização e crime no Oeste de Santa Catarina: processos-crime enquanto evidências, publicado pelos Cadernos do CEOM, no 25, dez. de 2005, Editora Argos, UNOCHAPECÓ. Membro do grupo de pesquisa Educação, Estado e Sociedade, da UNOESC. e-mail: delcio.marquetti@ unoescxxe.edu.br

** Acadêmica do Curso de História da UNOESC, Campus de Xanxerê.
} 
O Projeto Construção de Material Didático, integrante do Programa supracitado, assume como foco de trabalho o tema "História e Memória de Xanxerê", com o qual pretende reconstruir a memória da região. Dessa forma, priorizou-se a pesquisa em favor da produção de conhecimento em História Regional, desenvolvida basicamente por meio de abordagem e técnicas de pesquisa da História Oral, associado à organização de um espaço de memória acervo documental -, que promova a educação patrimonial e preservação de fontes. A cada etapa concluída, acadêmicos e professores produzem conhecimentos que são divulgados em escolas e em outros espaços, por meio de materiais como banners e documentários.

Levando em consideração o lugar onde os indivíduos processam a interação social, estabelecem vínculos e produzem uma história que possui sua especificidade, o Projeto valoriza a vinculação entre processo histórico e sociedade e desenvolve seus trabalhos de pesquisa a partir de eixos temáticos, os quais, em 2007, foram: "Colonização e imigração" e "Sindicalismo". O Projeto conta com acadêmicos que atuam na realização e transcrição de entrevistas e na produção de conhecimentos. Em 2008, também foi acrescentada a temática "Religiões e religiosidades".

O passado, seus estudos e seus usos constituem elementos importantes nos processos de construção e (re)definição de identidades coletivas. Nas últimas décadas, multiplicaram-se pesquisas voltadas a análises de fenômenos em escala micro. A construção de saberes históricos, a partir de problemáticas de caráter regional e local, com a preocupação de compreender fenômenos e eventos particulares em suas conexões com estruturas mais amplas, pode constituir-se excelente instrumento na formação de professores de História, e no ensino destes saberes a estudantes de educação básica.

A história da região de Xanxerê existe enquanto experiências vividas e registradas na memória de pessoas e na documentação de instituições que fizeram e fazem parte desse espaço. No entanto, a reconstituição desse passado sob o olhar da ciência histórica ainda precisa ser processada - um passado em fragmentos que precisa ser lapidado e transformado em conhecimento capaz de responder a necessidades educacionais e culturais da população local, e ao anseio de compreender-se a si mesma.

\section{Cultura popular/história oral: considerações teóricas}

Na abertura de sua obra A escrita da história, o historiador Peter Burke (1992) suscita um interessante debate a respeito de conceitos que sofreram redefinições num momento em que a ciência histórica abriu um imenso leque de novos temas, objetos e problemas, 
aproximando-se sensivelmente de outros campos do saber, como a Antropologia: "se a cultura popular é a cultura 'do povo', quem é o povo? São todos: o pobre, as 'classes subalternas', [...] são os analfabetos ou os incultos?” (BURKE, 1992, p. 21).

O conceito de cultura sofreu ampliações a partir do século XVIII, quando da consolidação do racionalismo iluminista e da idéia de que a humanidade deveria libertar-se das amarras da ignorância e da superstição, as quais foram construídas historicamente. $\mathrm{O}$ conhecimento e as artes tornaram-se mais valorizados, considerados atos de "cultivo" do indivíduo, comparado a planta, que precisa de cuidados especiais para crescer e produzir frutos. De lá para cá, quase sempre o termo cultura assumiu a conotação de erudição.

Nessa esteira, BURKE questiona: "E o que é educação? Apenas o treinamento transmitido em algumas instituições oficiais como escolas ou universidades? As pessoas comuns são ignorantes ou simplesmente têm uma educação diferente, uma cultura diferente das elites?" (1992, p. 21). Evidencia-se, nessa perspectiva, uma preocupação no sentido de se entender grupos não letrados ou que não têm acesso à cultura erudita como produtores de cultura. Antropólogos, historiadores e outros especialistas têm se interessado pelas ações das camadas baixas, ou populares.

As transformações ocorridas na segunda metade do século $\mathrm{XX}$, como a descolonização da África e da Ásia, e o despertar de movimentos em inúmeros países (movimento feminista, movimentos ecológicos etc) provocaram um deslocamento no olhar dos profissionais das ciências humanas. Grupos e sujeitos até então ignorados nas pesquisas científicas passaram a ser objeto em análises que visam a reconstituir e preservar experiências e identidades, bem como compreender melhor como se dão os processos de organização e atuação de operários, jovens, estudantes. Além disso, buscam ainda lançar luz sobre fenômenos peculiares que se manifestam no âmbito do regional, do micro.

Com a valorização dessas novas categorias sociais, surgiu o problema das fontes, pois são escassos os documentos que retratam suas trajetórias. Registros de inquisição, arquivos dos tribunais de justiça ou das prisões, obras que se dirigiram aos marginais, não produzidas por estes, são os principais documentos para a realização desses estudos.

É num contexto de efervescência da memória que as pesquisas extrapolam os círculos acadêmicos e dos especialistas e adentram nos processos coletivos de identidade cultural. As “palavras-chave são 'resgate', 'recuperação' e 'preservação' - todas pressupondo uma essência frágil que necessita de cuidados especiais para não se deteriorar ou perder uma substância preexistente", como aponta MENESES (1999, p. 12). 
O relato oral sempre foi a maior fonte de dados e transmissão de conhecimentos de uma geração para outra. Ensinamentos e tradições foram preservados e transmitidos por meio de rituais, danças, músicas, orações, conversas, e acabaram sendo encobertos por culturas ditas principais. Muito se perdeu em comunidades ágrafas, que não deixaram resquícios escritos que comprovem seus costumes - isso, no entanto, não significa que não possuíssem valores que merecessem ser resgatados. O desafio do historiador é, portanto, transformar a oralidade em escrita, para que seja utilizada como fonte fixa e verificável.

\section{Reconstituição da cultura popular cabocla}

A escritora goiana Cora Coralina (2002) conta uma interessante história sobre sua infância: Havia em sua casa um prato, o único que sobrou de um conjunto de louças com 92 peças, verdadeira relíquia preservada por sua bisavó. O prato evocava saudades, afetos, emoções, sentimentos e lembranças de doces e guloseimas, de família reunida, casamentos, batizados, festas do Divino. Os desenhos, em miniaturas de cor azul-forte, narravam cenas de uma linda história ocorrida na China. A princesinha Lui, prometida em casamento para um príncipe todo-poderoso, fugiu com um plebeu a quem amava. O pai, um velho mandarim, tramou vingança, mas os namorados foram avisados em tempo, graças à ajuda de um pombo que, por meio de uma argolinha no pé, levou-os uma mensagem enviada pela ama da princesa. Do tempo da bisavó foi o único prato. Os demais contavam outras legendas, traziam outros recados. Cora Coralina (2002) conta que quando quebrou o prato, sua bisavó chorou, e que ela também chorou ao lembrar da princesinha Lui, que já tinha passado a viver em seu inconsciente, como ser presente. Foi condenada a carregar no pescoço, amarrado por um cordão, um caco do prato quebrado, por meio do qual guardou na memória a história do prato, parte da trajetória e de vivências partilhadas por gerações em sua família. A história do prato azul-pombinho de Cora Coralina (2002) suscita importantes reflexões sobre a memória, suas interfaces e seu papel nos processos de constituição de identidades individuais ou coletivas.

A cultura de populações caboclas do oeste de Santa Catarina e no Sudoeste do Paraná constitui excelente laboratório de estudos históricos, antropológicos e etnográficos. Rica em crenças, costumes e rituais, suas práticas religiosas já foram consideradas aberrantes e estapafúrdias (LUZ, 1999), e, no entanto, trata-se de um conjunto de elementos historicamente construídos, a partir de vivências e influências partilhadas e recebidas em tempos e espaços diversos. 
Os portugueses, grupo étnico presente na formação da cultura cabocla, constituíram um certo catolicismo - em parte diferenciado do romano, pode-se dizer mais independente fruto de tradições de grupos que formaram a Península Ibérica, como celtas, romanos e árabes. Sofreram uma atuação mais intensiva do Tribunal da Inquisição, na tentativa de enquadrar os católicos nas práticas religiosas oficiais, e isso justamente num período em que muitos migraram para o Brasil. As lutas contra os mouros (árabes islâmicos) pela reconquista da Península tenderam a transformar figuras como São Jorge e São Sebastião em guerreiros protetores do povo.

Este catolicismo popular, rebelde a dogmas e rituais oficiais, foi então introduzido no Brasil, onde veio juntar-se a elementos das culturas africana e indígena. Caboclos, em sua maioria descendentes de portugueses e africanos, por muito tempo manifestaram tais crenças e costumes em práticas como Festa do Divino, Festa de São Sebastião, orações a São Jorge e simpatias para expulsar o ar da cabeça entre outras. Mais recentemente, em fins do século XIX e nas primeiras décadas do século XX, outro santo foi acrescentado ao panteão da região: São João Maria D’Agostini.

Ao longo do ano de 2007, foram entrevistadas quatro senhoras de origem cabocla, que vivem em Xanxerê e partilham sentimentos comuns em relação ao monge João Maria. Em suas trajetórias de vida, marcadas por dificuldades, encontraram, na crença no monge, a força necessária para superá-las. Em seus depoimentos, expressam a crença nos poderes do monge de prever acontecimentos, antever determinadas situações ou interferir nas leis da natureza, através de milagres ocorridos no seio de suas famílias, ou presentes na memória coletiva, como a multiplicação do pão e da couve.

As transformações ocorridas com o avanço tecnológico e, especialmente, com a vinda de migrantes gaúchos, colonizadores da região, fizeram com que essa rica cultura sofresse modificações e perdesse parte de sua beleza, e, embora permaneça viva na memória das avós entrevistadas, a exemplo da história do prato azul-pombinho, parece não ter o mesmo sentido para seus filhos. O filho de uma delas, por exemplo, recorda-se das histórias do monge por meio de informações sistematizadas em livros.

Para as depoentes: Ernestina Francisca Camargo (nascida em 1923) e Maria Ângela Vaseak (nascida em 1939) quando o fenômeno migratório de descendentes de europeus oriundos do Rio Grande do Sul encontrava-se em expansão - os ensinamentos que aprenderam com seus pais e pessoas mais velhas, especialmente em relação ao monge João Maria, fazem pleno sentido - e encontram-se carregados de profundos sentimento e afeto. A 
presença do monge é marcante, e as orações e pedidos ainda operam milagres no cotidiano de ambas.

Na vida de Emília Nunes de Araújo, nascida em 1925, o monge já foi figura importante e presente no imaginário de sua família. Hoje, ela questiona a veracidade da existência dos santos, influenciada pelas novas crenças de seus filhos. Influência muito clara do avanço do protestantismo na região, em suas manifestações mais recentes.

Elisabet de Sá, sobrinha de Maria Ângela Vaseak, nasceu em 1953 momento em que lideranças políticas da cidade, em sua maioria de descendência européia lutavam pela emancipação do município; num cenário já dominado pelos migrantes gaúchos e num período praticamente de consolidação do catolicismo oficial que considerava crendices a religiosidade dos caboclos. A depoente cresceu em meio a práticas antigas, mas foi muito mais influenciada pela igreja oficial, onde exerceu funções como catequista, ministra, e na qual ainda mantém atuação forte como agente de pastoral.

Já para Marcos Rosa da Silva, filho de Elisabet, nascido em 1976, o monge não tem o mesmo significado ou influência em sua vida. As informações que tem, adquiriu-as principalmente na escola. Marcos cita, com certa segurança, informações que se encontram hoje em manuais e obras de autores diversos, como nomes e datas: um conhecimento já sistematizado - "Sei o que aprendi na escola também”, diz.

Para as depoentes, o monge e seus milagres são informações recebidas de seus pais e de antigos que as vivenciaram, e constituem-se em conhecimento, uma vez que lhes é internalizado, fazendo parte de sua cultura. Uma cultura adquirida em práticas cotidianas e rituais, diferente do conhecimento adquirido na escola.

\section{Considerações finais}

Os relatos das depoentes, carregados de emoções, saudades e lembranças, parecem-se com o prato azul-pombinho, cuja bisavó insistia em manter, uma vez que representava forte ligação com seu passado - lembranças das quais não quer desfazer-se, mesmo que fragmentadas, como o caco do prato.

A religiosidade cabocla, marcada pela consideração às tradições e incorporada às vivências cotidianas, constitui-se herança, patrimônio individual ou coletivo transformado em resistência, cultura ameaçada e modificada por constantes transformações, que continua parcialmente viva, numa espécie de luta para não desaparecer. 
Nesse sentido, a conversa com os filhos era um momento considerado especial e exercido naturalmente, uma forma de preencher-lhes o imaginário: "Eles sentavam, contavam histórias, histórias lindas, que a gente dormia. Meu Deus! Nem queria acordar, de tão lindas que eram aquelas histórias. E assim, a gente foi crescendo nesse ambiente de respeito, de educação, de amor com o próximo, de cuidado também”, diz dona Elisabet.

Para as depoentes, participar da reconstituição dessa memória significa, mesmo sem terem freqüentado escolas formais, poder participar ativamente de um trabalho perpetrado pela historiografia oficial, no sentido da preservação de sua cultura.

O objetivo central dessa pesquisa é possibilitar que outras Coras Coralinas passem a integrar o universo literário e transmitam a outros todo um conjunto de sentimentos por elas vivenciados.

\section{Referências}

BURKE, Peter (Org.). A Escrita da História - novas perspectivas. São Paulo: UNESP, 1992.

CORALINA, Cora. O prato azul-pombinho. In: 2002. (Coleção literatura em minha casa. v. 1)

LUZ, Aujor Ávila da. Os fanáticos: crimes e aberrações da religiosidade dos nossos caboclos. 2. ed. Florianópolis: Ed. da UFSC, 1999.

MENESES, Ulpiano T. Bezerra de. A crise da memória, história e documento: reflexões para um tempo de transformações. In: SILVA, Zélia Lopes (Org.) Arquivos, patrimônio e memória: trajetórias e perspectivas. São Paulo: UNESP, 1999. P. 11-29.

\section{Fontes Primárias}

ARAUJO, Emília Nunes de. Cultura cabocla. Xanxerê: 26.07.2007. Entrevista concedida aos autores.

CAMARGO, Ernestina Francisca. Cultura cabocla. Xanxerê: 31.05.2007. Entrevista concedida aos autores.

SÁ, Elisabet de. Cultura cabocla. Xanxerê: 13.04.2007. Entrevista concedida aos autores.

SILVA, Marcos Rosa da. Cultura cabocla. Xanxerê: 18.11.2007. Entrevista concedida aos autores.

VASEAK, Maria Ângela. Cultura cabocla. Xanxerê: 05.06.2007. Entrevista concedida aos autores. 